This is the accepted version of the following article: Won, M. and Yoon, H. and Treagust, D. 2014. Students' Learning Strategies With Multiple Representations: Explanations of the Human Breathing Mechanism. Science Education. 98 (5): pp. 840-866., which has been published in final form at http://doi.org/10.1002/sce.21128 


\section{Students' learning strategies with multiple representations: Explanations of the human breathing mechanism}

Author Information $(*$ corresponding author)

1.* Name: Mihye Won

Address: $\quad$ Science and Mathematics Education Centre

Curtin University

Perth, WA 6845

Australia

Email: $\quad$ mihye.won@curtin.edu.au

2. Name: Heojeong Yoon

Address: $\quad$ Department of Science Education

Kyungpook National University

Daegu, Korea

3. Name: David F. Treagust

Address: $\quad$ Science and Mathematics Education Centre

Curtin University

Perth, WA 6845

Australia

Funding acknowledgement

Contract grant sponsors: Australian Research Council (DP110104254)

National Research Foundation of Korea (NRF-2011-356-B00037) 
Students' learning strategies with multiple representations:

Explanations of the human breathing mechanism

\begin{abstract}
The purpose of this study was to understand how students utilized multiple representations to learn and explain science concepts, in this case the human breathing mechanism. The study was conducted with Grade 11 students in a Human Biology class. Semistructured interviews and a two-tier diagnostic test were administered to evaluate students' learning strategies of integrating multiple representations. The functions of multiple representations (complementary, constraining, and deeper understanding) suggested by Ainsworth (2008) were adapted as the analytical framework to better describe the participating students' learning strategies with multiple representations (access complementary information, apply one representation to interpret the other, and evaluate representations). The categorization of students' learning strategies facilitated interpreting their diverse understanding in relation to the multiple representations. In addition to a summary of students' learning strategies, three case examples are presented to show how the framework was applied in the analysis and to discuss how the learning strategies interacted with students' understanding of the multiple representations and of the concept.
\end{abstract}

Key words: multiple representations, learning strategies, model, diagram, breathing

\title{
INTRODUCTION
}

Marx Wartofsky (1979) once wrote, "in science, as in much of art, human knowledge is achieved by means of representation" (p. xv). As a means to develop, understand, and communicate our experiences and thoughts, people have developed various forms of external 
representations (in both linguistic and non-linguistic forms) over the years. Especially in the field of science, diagrams, graphs, formulas, and other representations have immense rhetorical power, and they are at the center of scientific discourse (Latour, 1986). Bruno Latour (1986) observed that "Scientists start seeing something once they ... look exclusively and obsessively at [external representations] and [their] inscriptions" (p.15). Certain information is best presented in a particular form, and having an assortment of representations helps connect various aspects of a phenomenon; builds a more complete, deeper understanding of science; and communicates scientific ideas more effectively (Ainsworth, Prain, \& Tytler, 2011; van Someren, Boshuizen, de Jong, \& Reimann, 1998). Scientists use various representations in every aspect of their scientific practice to develop research designs, present the results, and elaborate and negotiate their ideas (Kozma, 2003). Experienced scientists move freely from one representation to another to grasp the substantial features of the topic rather than feeling restricted by the forms of representations (Kozma, 2003; Savelsberg, de Jong, \& Ferguson-Hessler, 1998). de Jong and his colleagues (1998) defined expertise in terms of the flexible use of multiple representations: "Expertise is quite often seen as the possession and coordinated use of multiple representations of the domain" (p.32).

Because understanding and communicating science involves utilization of multiple representations, proficient science learners need to understand how to create, interpret, translate, and assess different representations (Ainsworth et al., 2011; Tytler, Prain, Hubber, \& Waldrip, 2013). Many educators have investigated the impact of multiple external representations (MERs) on students' learning of science (see for example, Adadan, Irving, \& Trundle, 2009; Goldman, 2003; Waldrip, Prain, \& Carolan, 2010). Researchers have found that integrating multiple representations (especially visual ones) could afford a better conceptual learning environment for 
many students (Dori \& Belcher, 2005; Gilbert \& Treagust, 2009; van Someren, Reimann, Boshuizen, \& de Jong, 1998). As an example, Tsui and Treagust (2003) found that when high school students learned genetics with multiple representations through the hypermedia software Biologica, they improved their reasoning in Mendelian genetics problems. Harrison and Treagust (2000a) and Tasker and Dalton (2008) also found that students had more scientific understandings of particles and their interactions when they were provided with multiple representations using models and computer animations, respectively.

Despite their advantages, students may not always gain the full benefits of integrating multiple representations in their science learning. Students often display difficulty in interpreting, connecting, and translating various representations to develop and communicate their ideas (Ainsworth, Bibby, \& Wood, 1998; Kozma, 2003; Schijf \& Simon, 1998). Indeed, students tend to focus on 'surface features' of a representation, overload themselves cognitively, and fail to link the represented content to build a coherent understanding (Seufert, 2003). In those cases, students prefer to use only one representation, and ironically they may be more successful in forming an explanation with one representation than when they were erroneously integrating multiple representations (Scanlon, 1998; Schijf \& Simon, 1998). When students do use multiple representations in their learning, they are often hampered by the features of different representations and fail to effectively build and communicate their understanding (Kozma, 2003; Lowe, 2003; Schnotz \& Bannert, 2003).

Wartofsky (1979) gives an insight into understanding this learning difficulty. He observed that a commonly accepted representation is not the exact replica of the object but we 'see' it as one. For example, if we draw a cup, we put an ellipse for the top part of the cup rather than a circle. When we view the ellipse in the diagram, we automatically interpret it as the cup being in 
a circle shape rather than a tilted oval shape. Like so, even the simplest diagrams display canons of representations, and the viewer needs to process the representational conventions to understand what it represents and how it could be similar and different from the 'real' object. Because interpreting and producing a representation demands proficient understanding of the form and the content of the representation, getting the message of a particular representation is not automatic. Rather, it is an acquired skill.

Among many different representational modes, research has shown that integrating analogical models into science class is an effective way to visualize and explain a phenomenon to enhance students' learning (Aubusson, Harrison, \& Ritchie, 2006; Coll \& Lajium, 2011; Harrison \& Treagust, 2000b). Science education researchers often use the word 'model', and there is much variation in the use of this term from physical scale models to pedagogical analogical models to conceptual/mental models (Harrison \& Treagust, 1998, 2000b). Pedagogical analogical models are analogs often in the form of physical artifacts that teachers adopt in order to bridge between the target concepts and the students' experiences. They not only provide representations of abstract concepts or unobservable phenomena to students (e.g., the double helix for DNA structure and ball-and-stick for organic chemistry molecular structure), but also help students to talk about their ideas, improve on their explanations, make predictions, and generate mental models (Dagher, 1995; Treagust, Chittleborough, \& Mamiala, 2003). Teachers often use various analogical models to help students learn science, but researchers have found that students' learning with analogical models does not always turn out as anticipated (Gilbert \& Osborne, 1980; Gobert et al., 2011; Grosslight, Unger, Jay, \& Smith, 1991; Hesse, 1966; Treagust, Chittleborough, \& Mamiala, 2002; Wilbers \& Duit, 2006). An analogical model, like any other representations, is not an exact replica of the reality and inevitably involves negative 
analogies (which do not correspond to the target concept) as well as positive ones (which fit to explain the target concept) (Gilbert, 2005). Yet, many students are not aware of the difference between the model and reality (Grosslight et al., 1991; Hesse, 1966), and believe that analogical models are exact scientific phenomena rather than being analogs (Treagust et al., 2002). Such lack of comprehension on the analogical model as a form of representation often leads to erroneous interpretation of the model, undermining the potential pedagogical benefits of adopting analogical models.

To gain pedagogical and epistemological benefit from analogical models, or any other representations for that matter, students need to recognize the main purpose of adopting the particular representations and where is a direct correspondence between the representation and the target concept and where the correspondence breaks down (Chittleborough, Treagust, Mamiala, \& Mocerino, 2005; Gobert et al., 2011; Harrison \& Treagust, 1998). Researchers also recommend that teachers need to help students recognize limitations of the representation for their meta-representational skills (Glynn, 2008; Treagust, Harrison, \& Venville, 1998). When understanding the correspondence and limitations of a representation, students need to interpret that particular form of representation and reconstruct it in relation to other types of representations, such as diagrams, equations, and texts (Seufert, 2003). Teachers could supply other representations to support such integration and translation processes for students.

Understanding and reconstructing different representations in relation to one another is a highly personalized process, and even with the same set of representations, students might utilize them in quite different ways (Eilam, 2013), depending on their prior knowledge of the topic (Cook, Carter, \& Wiebe, 2008), the way the representations are presented (Treagust \& Tsui, 2013), the nature of representations (Treagust \& Tsui, 2013), and students' meta-representational 
competencies (diSessa \& Sherin, 2000). Considering the complexities of learning with multiple representations, researchers recommend that teachers need to examine what information actually becomes accessible to students and how they might use the information and then find a more effective way of integrating multiple representations to assist in students' learning processes (Ainsworth, 2008; Ainsworth et al., 1998; Goldman, 2003; Prain, Tytler, \& Peterson, 2009; White \& Frederiksen, 1990; Wu, Lin, \& Hsu, 2012). To the best of our knowledge, however, there is no unifying analytical framework for analyzing the use of multiple external representations. Without any framework for analyzing students' explanations, teachers and researchers are often left to resort to their own devices to examine the patterns of students' use of multiple representations. As noted by many of the science education researchers referred to earlier, understanding these patterns is necessary for knowing the depth and breadth of students' understanding. We consider that analyzing how students use multiple representations in their learning process and providing feedback to the students is consistent with the goal of biology education recommended by the National Research Council (2009). These recommendations are developed to help students build a deeper understanding of biological systems with a variety of representations.

In this study, we have adapted Shaaron Ainsworth's $(2006,2008)$ framework to analyze the strategies that students use for explanations when presented with multiple representations. Her framework was originally introduced as design guidelines for digital learning materials and environments rather than as an analytical framework for teaching and learning. Yet, we found the different functions of multiple representations from Ainsworth's framework could be used to analyze the different learning strategies that students adopt when explaining phenomena presented with multiple representations. In our view, these functions of multiple representations 
are anticipated interpretation strategies from the learning material designer's view. Students' learning strategies with representations may not exactly align with the designer's anticipated functions, but still can fall into any of the categories in this framework. Subsequently, these categories were the essential part of the analysis to understand the strategies that students used when learning from different forms of representations.

Ainsworth's framework presents three distinct functions of multiple representations for learning, namely being complementary, constraining, and constructing. The first function of multiple representations is providing complementary aspects of information and facilitating different content processing skills, just like showing a series of pictures of front, back, and side views for a concept. For the concept of human breathing mechanism, for example, a simple belljar model can easily illustrate the relationship of the muscle movement to the air movement while an anatomical diagram can provide information on related body parts during breathing. On the other hand, a certain combination of representations can constrain interpretation of other representations by setting the boundaries, such as a photo with a caption (see for example, Pozzer \& Roth, 2003). One representation that is more specific or familiar to students can guide the interpretation of other representations that are less familiar or complex to them. For example, in a combination of a bell-jar model and an anatomical diagram, the physical analogical model is simple and familiar enough to students to function as the primary representation that delimits the interpretation of the anatomical diagram due to the complexity of human body parts. The other function of multiple representations is to help construct a deeper understanding of the concept. When multiple representations were integrated and evaluated against one another, they could provide substantial features of the phenomenon that may not be obvious from each individual 
representation. Ainsworth (2008, p. 198) quotes Kaput (1989) to emphasize that "the cognitive linking of representations creates a whole that is more than the sum of its parts."

As illustrated in Figure 1, based on these three functions of multiple representations, we categorized students' strategies when they integrated multiple representations to learn a science concept and used them as the analytical framework. Each strategy in the framework corresponds to a function of multiple representations in Ainsworth's framework: (1) access complementary content of representations; (2) apply the understanding of one representation to interpret the other; and (3) compare and evaluate multiple representations to construct deeper understanding of the concept. Each strategy has two or three subcategories as in Ainsworth's framework. This framework was critically evaluated throughout the data analysis process in terms of its usefulness in identifying students' actual learning strategies.

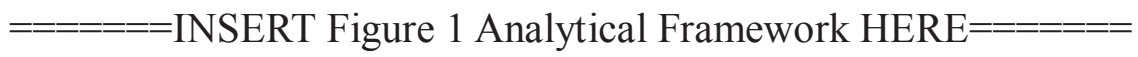

In the science education literature, 'multiple' (as in multiple representations) could mean various dimensions, such as different representational modes with different degrees of abstraction (like physical objects, photos, diagrams, graphs, texts, etc.), different scopes or representational levels (such as macro, micro, sub-micro, and symbolic), or different topics or content domains (that is, ecology, energy, evolution, etc.) (Treagust \& Tsui, 2013). For the purpose of this paper, we focus on multiple representations as different representational modes. In the analysis, we included rich details of students' sense making processes to show the dynamic interaction between different representations (a pedagogical analogical model and an anatomical diagram), between students' understanding of the topic and of the nature of representations, and between the way the representations were constructed, presented, and reconstructed in context. Through this analysis, we attempted to show how Ainsworth's framework has been adapted to 
help science teachers and educational researchers understand more deeply how students use multiple representations for their learning and communicating of science concepts.

\section{RESEARCH METHODS}

\section{Research Design}

This study is part of a larger research project examining the roles of scientific multiple representations in contributing to conceptual understanding. The analytical focus was the students' sense-making of a biology concept (human breathing mechanism) through their own use of multiple representations. The three research questions that guided the study were:

(1) What strategies do students adopt when learning and explaining science concepts with multiple representations?

(2) How do the different strategies enable students to understand and explain science concepts?

(3) How does the analytical framework, which was adapted from Ainsworth's functions of multiple representations, facilitate understanding of students' learning with multiple representations?

We chose a case study design to provide a rich description and in-depth analysis to answer these questions (Yin, 2009). The researchers conducted the study in one biology class over a sustained period and collected multiple sources of data (e.g., videos and field notes on classroom scenes, interviews with students and teacher, students' diagnostic test results, etc.) to triangulate the outcomes (Cohen, Manion, \& Morrison, 2011; Merriam, 2009). Through this case study, we did not aim to make a generalization based on a large set of data (Yin, 2009). Rather, by offering a detailed picture of how students' particular experiences interact with their use of multiple 
representations, we aimed to provide an insight on how we can effectively interpret students' use of multiple representations referring to Ainsworth's analytical framework. This analytical generalization (rather than statistical generalization) is to help science education researchers move forward to build a stronger theory on how to help students' use of multiple representations (Cohen et al., 2011).

\section{Contexts}

This study was conducted in one Grade 11 Human Biology class at a girls' K-12 school in Perth metropolitan area in Australia. Human Biology is a popular science subject for senior secondary students at the school, and consequently, there were multiple Human Biology classes. We observed the class taught by Mr. Duncan, who, as the head of science department at the school, has been involved in educational research projects prior to this study. Mr. Duncan has been teaching Human Biology for eight years at that school and overall has 25 years of teaching experience. The usual mode of class was a lecture (typical teaching in the last two years of high school). At other times, students participated in practical work or group activities in the laboratory. His lessons were tightly organized to give students the overall framework of a concept and then go into the details. While Mr. Duncan explained a concept, he often checked if students understood the concept, and they were encouraged to ask questions and also take notes. Students often commented that his lessons were clear and fit with the way they think.

Like many other biology teachers, Mr. Duncan incorporated a lot of representations in his teaching, such as videos, simulations, diagrams, and photos. One particular aspect about his teaching was that he intentionally drew a lot of diagrams on the board, helping students to follow up on what he was drawing and thereby identify the structure or important aspects of the 
diagram. Once he completed a drawing, he often asked students what the diagram represented and how the diagram did and did not correspond to the target science concept.

\section{Study Topic}

Among many human biology concepts, the breathing mechanism was chosen as the study topic for two reasons. First, while human respiration involves both internal and external respirations, previous conceptual research studies have mainly focused on internal respiration (Anderson, Sheldon, \& Dubay, 1990; Seymour \& Longden, 1991). Internal respiration involves chemical reactions in cellular level to obtain energy, and external respiration is often called breathing in and out of air, caused by muscle contraction and relaxation around the lungs. As shown in a textbook diagram (Figure 2), when we breathe in, the diaphragm and the intercostal muscles contract. This contraction causes the thoracic cavity to expand and the volume of the lungs increases. The increase in the volume of the lungs causes a decrease of the gas pressure in the lungs, generating a pressure difference between the inside of the lungs and the atmosphere. Air then flows from the outside into the lungs. The opposite procedure occurs during exhalation. In analyzing students' responses from a diagnostic instrument on respiration, Mann and Treagust (1998) found that the majority of students had little knowledge of the mechanism of external respiration or the causes of the change in lung volume. Even after biology lessons, students thought that the lungs increased in volume by themselves or air entering the lungs caused them to expand. Investigating this study topic, we intended to examine how students integrated various representations to overcome common alternative conceptions and construct better understanding of the human breathing mechanism.

$======$ INSERT Figure 2 Textbook Anatomical Diagram HERE======= 
The second reason to choose this topic was that the human breathing mechanism is frequently taught with multiple forms of representations such as models, simulations, diagrams, and texts (Wu et al., 2012). Among many representations, a bell-jar model is a popular pedagogical analogical model that many biology teachers adopt when teaching the topic. The bell-jar model is designed to illustrate that the inhalation and exhalation is directly related to the muscle movement and the change in the lung volume (Eilam, 2013; Yip, 1998). As shown in Figure 3, the bell-jar model consists of a glass jar, two balloons, and a rubber sheet. The jar symbolizes the chest cavity, two balloons stand for the lungs, and the bottom sheet is for the diaphragm. When the rubber sheet (diaphragm) moves down, the balloons (lungs) expand. The lowered pressure inside the balloons causes the outside air to flow in (inhalation). When the rubber sheet moves up, the balloons shrink in the volume. The higher pressure pushes the air inside the balloons to move out (exhalation).

\section{$=====$ INSERT Figure 3 Bell-Jar Model Diagram HERE $=====$}

Like many other analogical models, this bell-jar model enables learners to see and understand some aspects of a scientific phenomenon that is beyond their immediate perceptions (Gilbert, 2004). This analogical model of breathing has inherent characteristics of emphasizing some features of the human respiration mechanism while hiding some other less salient features. For example, balloons represent the lungs in the model to give an impression that the lungs are hollow bags rather than filled with hundreds of millions of alveoli. The length of the rubber sheet is another discrepancy. For inhalation, the rubber sheet moves downward and gets stretched while the diaphragm moves in the same direction but become shortened. The anatomical diagram of the human lungs (as seen in Figure 2) often accompanies the analogical model because it displays the structure of the lungs more accurately than the model. Since these representations 
contain slightly different emphases and information, students need to utilize their representational knowledge and strategies to construct better conceptual understanding from them. The authors of this paper concluded that studying how students use this particular analogical model along with other representations would offer us a good insight on students' learning strategies involving multiple representations. In order to investigate how students interpreted the analogical model in relation to pictorial and verbal representations and how the combination of these representations operates for each student, we adopted Ainsworth's framework for the students' explanatory strategies involving multiple representations.

\section{Data Collection}

Class Observations. As participant observers, the researchers regularly visited the school at least twice per week and observed Mr. Duncan's class during a three-month period as part of a larger study. Once introduced, the researchers sat at the back of the classroom, took field notes, and videotaped the class interactions. During individual or group activities, the researchers casually interacted with students asking questions about their activities. For the topic of human respiration, the teacher spent four hours over one week and we recorded the sequence of activities and the modes of multiple representations used in each class. We were also able to capture the class members' verbal interactions on the video which were later transcribed.

Interviews. A week after the four lessons on the topic, we asked students to elaborate on their understanding of the human breathing mechanism with the model and diagrams using a semi-structured interview protocol (Cohen et al., 2011). In the interviews, we sought to determine how students integrated the different representations to explain their understanding of the human breathing mechanism. Eight students volunteered to participate in the interview. We paired up the students to help them feel comfortable around the interviewer who conducted the 
interview in an empty classroom during an individual study hour. As a prop for the interview, two sets of diagrams were prepared. One was a diagram of the bell-jar model that the teacher showed in class (please refer to Figure 3) and the other was a diagram of the lungs from the students' textbook (please refer to Figure 2). Any texts on the diagrams were deleted prior to the interview, and the students were asked to explain the breathing mechanism using the diagrams. The interviewer encouraged the students to draw or write on the diagram as well as verbally explain their ideas during the interview. Each interview session lasted between 20-30 minutes and was audio-recorded and later fully transcribed.

Diagnostic Test. One week after the topic was taught, each of the 22 students in the class answered a text-based two-tier diagnostic test on the human respiratory system. This test was used to compare students' text-based understanding with their diagram-based explanation of the human breathing mechanism. The diagnostic test, developed by Mann and Treagust (1998), consisted of 12 items dealing with common alternative conceptions on human breathing mechanism and gas exchanges processes. The internal consistency (Cronbach's alpha) of the diagnostic test was 0.71 for this study, an acceptable value for cognitive tests (Adams \& Wieman, 2011).

For this article, we focused on the two items of the test that dealt with the structure and the mechanism of the human respiratory system in relation to the analogical model that the teacher used in class. One of the items reads, "Each lung is a large hollow sack that is like a balloon that expands and contracts to get air into and out of the lung (item \#6)." The other reads, "When we breathe in, the lungs expand in volume because the thoracic cavity expands (item \#9).” 


\section{Data Analysis}

In order to ensure the internal validity and reliability of the findings in this research about the students' learning strategies with multiple representations, we obtained data from multiple sources about the same events with the same students using different methods to ensure trustworthiness of the findings (Cohen et al., 2011). Once the authors collected various data from classroom observations (both with and without video), student interviews, diagnostic pencil-andpaper tests, and discussions with the teacher, we organized the data for each individual student. Each individual student's digital media file, transcript, annotated diagrams, and diagnostic test results were compiled and tabularized. Because this study involved micro-analysis of each student's responses, the authors independently coded each student's understanding of the concept, interpretation and use of each representation, and strategies of using multiple representations in terms of Ainsworth's framework. Especially for each strategy of integrating multiple representations, we listed the patterns and specific evidences from the students' annotations and verbal explanations (please refer to Table 1). Once the data were coded, we reviewed the coding and discussed any disagreements in each other's analyses. As the data were not quantifiable, we were not able to use an inter-rater measure such as Cohen's kappa. The authors of this paper met on a regular basis to draw themes and discuss possible alternative interpretations of the data before reaching a consensus based on a clear balance of argument (Erickson, 2012).

After the initial analysis was completed, we shared our findings with the participating teacher, Mr. Duncan, for member checking (see Merriam, 2009). We incorporated his understanding of the situation into the final analysis, presented in this article. In this manner, we asserted that our analysis of the data illustrated the students' different strategies of integrating 
multiple representations as presented in our theoretical framework (Ainsworth, 1999, 2008), thus ensuring construct validity of the research (Cohen et al., 2011). Consequently, in this research, primarily with qualitative data, we made every effort to validate the findings so that they were reliable, ensuring their trustworthiness (Merriam, 2009).

$=====$ INSERT Table 1 Coding Scheme HERE $=====$

\section{FINDINGS}

\section{Setting the Scene: Teaching Breathing Mechanism with Multiple Representations}

When asked about his use of multiple representations, Mr. Duncan said, "It's a very deliberate strategy to use [representations]. Full stop." He believed that his students, like himself, cannot think well in abstract terms and they "need something concrete in front of them" to learn biology. In class, Mr. Duncan usually adopted a lot of visual aids to explain biology concepts, and he strongly encouraged his students to draw diagrams and annotate them to learn and review the content. He was aware that students might believe that a diagram is an accurate anatomical depiction of a human body and function just because he used it in class. Thus, Mr. Duncan often used more than one visual representation to provide different views and asked metarepresentational questions, such as "what's wrong with this diagram?" or "how is this diagram different from the previous one?" His teaching style was well displayed for the topic of human respiration.

During the second week of the topic on the human respiratory system, Mr. Duncan explained the structure of the lungs and showed a bell-jar model to illustrate the human breathing mechanism. The bell-jar model visualizes the action of the diaphragm and the change in the lung 
volume during the breathing process. When he held the bell-jar model, he mentioned the strengths and weaknesses of the model first.

Mr. Duncan: This model represents your thoracic cavity. It is a good model in that it has a diaphragm in here, and ... [I can] move it downward. But it is a poor model in that the rest of the thoracic cavity is fitted ..., not flexible. The ribs cannot move [in this model]. And obviously, there are muscles internally as well.

He explained that this model visualizes the thoracic cavity and the diaphragm movement, but it is not a perfect replica of the lungs because it has limitations in visualizing all the components of the chest cavity such as ribs or intercostal muscles, and their movements. By explicitly talking about the limitations of the bell-jar model, Mr. Duncan was not only guiding students to avoid common mistakes while interpreting this particular model as biology educators have suggested (Eilam, 2013). He was also modeling how to critically analyze a representation and helping students to build meta-representational understanding. Then, he resumed explaining what happens during the breathing process with the bell jar model.

Mr. Duncan: What this [model] allows us to see is, when the breathing muscles contract, when the diaphragm contracts, it goes downward (pulls down the rubber sheet). It increases the volume of the thoracic cavity slightly. So it decreases the air pressure in your thoracic cavity just slightly. Air always flows from high pressure to lower pressure. So the movement of the diaphragm creates low pressure inside your chest and air simply flows in. When you relax (releases the holder of the rubber sheet), your diaphragm moves back up to its normal position and squashes up the volume of thoracic 
cavity slightly. Now the inside of your thoracic cavity becomes high pressure than outside. Therefore air flows outward from high to low pressure. So if you grab the holder and move it down, you can see the balloons slightly inflate. Up and down, up and down.

Manipulating the bell-jar model, he explained the inhalation mechanism in three steps: 1) the diaphragm contracts and moves down, which increase the volume of the thoracic cavity, 2) the increased volume decreases the pressure of the lungs, and 3) the air flows in to the lungs due to the pressure difference. A similar description was given but in the opposite direction for the exhalation mechanism. After the explanation, he kept pulling and pushing the rubber sheet of the model to show how the movement of the rubber sheet (diaphragm) changed the volume of balloons (lungs). He added a few more sentences on the role of muscles to create the volume and pressure difference in relation to the atmosphere, and then asked the students to go over the textbook and revise for themselves on this topic, leaving the task of integrating other representations with the bell-jar model to the students. Thus, in this manner, the interpretation of the anatomical diagram in relation to the bell-jar model in our interviews was less influenced by the teacher's immediate instruction with the diagram, but by the students' own effort and integration skills that had been supported by the teacher over time. This particular situation enabled us to have confidence in the interview because students could not just repeat what the teacher had presented in class, but they had to actively seek a coherent understanding beyond memorization. 


\section{Students' Strategies with Multiple Representations When Explaining the Breathing}

\section{Mechanism}

When we probed students' understanding of the breathing mechanism through interviews and the two-tier diagnostic test items, we noted that in the interview all students were able to explain the breathing mechanism referring to the bell-jar model. They understood the breathing mechanism in relation to the diaphragm movement and the changes in lung volume. However, when they were asked to integrate the anatomical diagram with the bell jar model, the students gave quite different answers and displayed various strategies with the representations. Some students critically examined the form and content of each representation, integrated the representations in multiple ways, and gave a thorough explanation of the concept. Some others relied on their understanding of the bell-jar model to interpret the anatomical diagram. The application strategy was sometimes carelessly adopted without paying close attention to the characteristics of each representation and misled the understanding of the target concept. In this article, we describe how the multiple representation strategies were adopted and utilized by three focus students, Adele, Brianna, and Carly (each name is a pseudonym) with reference to the analytical framework.

\section{Adele's Multiple Integration Strategies and Critical Understanding of Representations}

Adele is one of the "self-learners", according to Mr. Duncan, who voraciously read textbooks and extracted even detailed information that Mr. Duncan did not verbalize in class. She was not recognized as the most intelligent student in the class but she enjoyed the subject and studied skillfully. Two years after the data collecting period, she is currently pursuing biomedical studies at the university. Not surprisingly, Adele was one of the students who had sufficient knowledge in the science domain and of the representations to be able to demonstrate a coherent 
understanding of the breathing mechanism using the analogical bell-jar model and the textbook diagram. Using Ainsworth's analytical framework, we show how Adele used the different representations in an integrated manner to display a coherent, deeper understanding.

The first strategy we identified from Adele's interview was her use of multiple representations to access complementary information (corresponding to the complementary strategy with multiple representations). Although the students did not have time to label a similar diagram for this specific topic in class, Mr. Duncan generally provided students with sufficient time to work on diagrams to label the body parts and write explanations after his lecture. In the interview, Adele did not hesitate to write on the diagrams, immediately labeling and writing as shown in Figure 4. She was a bit uncertain how to label the lungs and the chest cavities in the diagrams, but Adele successfully completed the diagram with nearly everything written down, including the chest cavity, the lungs, the diaphragm, the intercostal muscles, and the ribs. She even named the pleural membranes and fluid, which Mr. Duncan did not mention in class but which were explained in the textbook.

\section{$=====$ INSERT Figure 4 Adele's Annotation HERE $=====$}

If we look closely at Adele's annotations, we can see that she used the model diagram and the anatomical diagram in a complementary manner. She used the anatomical diagram mainly to indicate all the corresponding body parts and used the model diagram to explain the breathing mechanism in terms of the muscle contraction, the changes in the lung volume and pressure, and the airflow due to pressure difference. Although these two representations are not, by their nature, exactly complementary, Adele decided to use different representations as if they were complementary for effective communication of her understanding. She wrote down her explanation next to the model diagram and appeared to have understood both the model and the 
diagram to explain the breathing mechanism procedures fairly well. When asked to explain what she had written, Adele reiterated what each part represented and elaborated on the process of breathing with exactly the same logic and sequence that Mr. Duncan explained in class. She spoke quickly without any hesitation as if she had rehearsed her response beforehand.

When looking at her labeling of the model diagram closely, however, we found a unique interpretation of the model. For the rubber sheet on the bell-jar model diagram, Adele wrote, "[it] represents the diaphragm and intercostal muscles." Mr. Duncan explained that the rubber sheet represents the diaphragm. The intercostal muscles are neither located beneath the lungs like the diaphragm nor move down when we breathe in. What did Adele mean by the rubber sheet representing both the diaphragm and the intercostal muscles? As we examined her verbal explanation of the diagrams, we gained a better picture of her interpretation.

Interviewer: Okay, so you are ready to explain. Would you explain what you drew [on the diagram]?

Adele: ... Okay. The balloons represent the lungs and then the chest cavity represents the whole bit [the glass jar]. And then that (points at the rubber sheet on the diagram) represents the diaphragm and intercostal muscles, well mainly the diaphragm because you can't have the intercostal muscles here, because it [the model] doesn't explain all the science.

Interviewer: Right.

Adele: But anyway, the diaphragm and the intercostal muscles contract, this is inhalation, so they contract right there, and that's shown there also (points at the anatomical diagram below) when the diaphragm's contracting and those intercostal muscles there contract. And then they increase the volume of the 
lungs because the pleural membrane pulls on the lungs and the lungs expand so that's shown by the increase in the balloon. That one, actually, no, it's not, actually. And so this lowers the... it increases the volume of the lungs and decreases the air pressure and air flows from high to low pressure so the air flows out there into there because that is a low pressure air and out there is higher pressure.

Interviewer: Oh, okay.

Through her verbal explanation, we could infer why Adele wrote the rubber sheet 'represents the diaphragm and intercostal muscles.' She was initially trying to find the correspondence between the anatomical diagram and the bell jar model. Because her understanding of the anatomical structure was primarily based on the anatomical diagram rather than on the bell-jar model, she was applying her understanding of the anatomical diagram to explain the bell jar model and its anatomical correspondence (the application strategy integrating multiple representations). She was aware that the bell-jar model was a simple model, as Mr. Duncan mentioned in class. An analogical model can explain some aspects of science involved, but cannot sufficiently represent "all the science." Maybe with Mr. Duncan's repeated question of 'What's wrong with this diagram?' in class, Adele already knew that she needed to be critical about the correspondence between a model and the target concept, and the correspondence cannot be automatically established. With such analytical understanding of representations, she recognized the primary purpose of the model: it was to show that the muscle movements are the direct cause of the volume/pressure change of the lungs for human breathing process. Because both the diaphragm and the intercostal muscles were involved in the process, she extended the analogy of the rubber sheet. Even though she knew the intercostal muscles are not merged with the diaphragm, she 
reinterpreted the analogy of the model and wrote down both muscles for the rubber sheet. This imprecise or flexible interpretation of the model was Adele's attempt to integrate multiple representations so that she could explain the substantial features across the representations.

In the later part of her explanation, Adele encountered another discrepancy of the modelthe lack of pleural membranes and fluid. When she was trying to explain the breathing mechanism, Adele found that there was no corresponding part for the pleural membranes and fluid in the bell-jar model. The limitation of the bell-jar model, however, did not vex her. She critically evaluated the correspondence between two representations and compared them against her understanding of human breathing mechanism (the evaluation strategy integrating multiple representations). After the comparison and evaluation of the representations, she concluded that the anatomical diagram better fitted with her understanding and the nonexistence of the pleura was another shortcoming or negative analogy of the analogical model. She did not pursue to find the correspondence and link those two representations any more at this point. She decided to drop the representation that did not illustrate her understanding and instead chose to use the anatomical diagram to better explain the breathing mechanism. Dismissing one representation (the bell-jar model) rather than trying to integrate multiple representations did not mean that she was not able to build a comprehensive understanding of the concept. Rather, it was the opposite. The bell-jar model was no longer necessary for Adele because she already developed an understanding of the breathing mechanism based on the anatomical diagram that was more sophisticated and robust than the bell-jar model could illustrate. She outgrew the original purpose of the bell jar model by being able to interpret and explain the more complicated representation (in this case, the anatomical diagram), and she decided that she did not need to adopt both representations to explain the concept (Ainsworth, 2008). 
Adele's critical evaluation of representations was apparent in her two-tier diagnostic test results. Although the balloons represent the lungs in the bell-jar model, Adele did not choose a statement that the real lungs are two large hollow sacks like the balloons (Item \#6). She also selected a statement that the pleural membranes and fluid play an important role in the breathing mechanism even though the bell-jar model did not show them (Item \#9). In a way, the diagnostic test itself was asking students to be critical of the simple bell-jar model and move beyond it to construct a scientific explanation of human breathing mechanism. Adele was doing just that and answered the two-tier diagnostic test items correctly.

From the analysis of Adele's interview, we can see how she adopted different strategies with those two representations (the model and the anatomical diagram) as the interview progressed. She was confident to explain her interpretation of the representations and the concept. Thanks to her analytical understanding of the concept and the different forms of representations, she was able to adopt, integrate, and select the representations successfully. It is interesting to note that Adele utilized all three strategies of multiple representations that we listed - access complementary information, apply one representation to interpret the other, and compare and evaluate to construct deeper understanding. However, the shifting utilization of the representations during the interview showed that she did not think deeply about ways to integrate the representations until she was explicitly prompted to show her understanding with the given representations.

\section{Brianna's Limited Utilization of Representation Strategies}

As noted earlier, the students in Mr. Duncan's class supplied relatively good explanations of the breathing mechanism using the bell jar model in the interview. When they were asked to integrate the anatomical diagram into their explanation, though, most of them mainly applied 
their understanding of the model to interpret the anatomical diagram rather than adopting multiple strategies. These students did not display critical understanding of the form of representations in regard to recognizing the negative analogs of the bell jar model or attending to different features of representations, despite Mr. Duncan's modeling of such critical evaluation of representations. They were partially successful in linking or expanding their understanding of the representations to develop a deeper understanding of the topic beyond the scientific content presented by the bell-jar model.

Brianna was one of those students. She was not one of the vocal students who would ask questions or volunteer answers in class. She would sit quietly, diligently taking notes on Mr. Duncan's lecture and diagrams. When asked to elaborate on her understanding of the breathing mechanism, Brianna was able to give a short, to-the-point answer. Maybe because of the way the interview questions were phrased, her answer sounded as if she wanted some confirmation from the interviewer.

Interviewer: So can you tell me...Basically, what is breathing? What's happening to your body?

Brianna: So like, your diaphragm is contracting, your intercostal muscles are contracting? ... And then the volume in your lungs increases, ... so the pressure drops and air's sucked into your lungs. And that's when you inhale.

She understood that the relative pressure difference was the cause of air movement for breathing, and both the diaphragm and the intercostal muscles were involved in the breathing mechanism. When she was given the diagram of the bell-jar model, Brianna explained the main points of the analogical model to her partner who had missed one of the lessons.

Interviewer: Can you explain the diagram of the bell-jar model to Charlotte? 
Brianna: Well, that's like... The lungs are similar to the balloons. ... Your lung cavity is the glass bottle, and you have, your diaphragm is that (points at the rubber sheet). When you contract your diaphragm, it makes the air rush in. Do you get it? Like that's the...

Charlotte: Oh, that's creating...

Briana: Yeah, that's creating a low pressure, so it'll get sucked in.

Brianna was not as elaborate in her explanation compared to Adele. Yet, she seemed to have grasped the intention of the analogical model. Pointing at each element of the model and linking it to its corresponding body part, she succinctly explained the model to guide her partner's interpretation of the model. She did not refer to the anatomical diagram nor mentioned the shortcomings of the model (at least in terms of intercostal muscles).

After explaining the model, Brianna was asked to annotate the anatomical diagram. She noted that she remembered seeing the diagram from her textbook, and she immediately started labeling the body parts on the diagram (see Figure 5). Brianna quickly wrote down the relevant body parts, such as diaphragm, intercostal muscles, lung (chest) cavity, and ribs. She also drew a few arrows to indicate the directions of the movement of air and the muscles. The annotation of the anatomical diagram was rather simple without addressing more detailed information of the diagram (except the inclusion of the intercostal muscles). Her interpretation of the anatomical diagram seemed almost parallel to her explanation of the bell jar model or her initial explanation of the breathing mechanism. Brianna seemed to apply her understanding of the bell jar model to interpret the anatomical diagram (the application strategy integrating multiple representations).

For the most part, she was relating her understanding of the model to the anatomical diagram without mistakes. At one point, however, she could not figure out some parts of the 
anatomical diagram, especially the relative location of the diaphragm. In the anatomical diagram, the diaphragm is represented in orange color with some thickness change and the pleural membranes and fluid are represented in blue all around the cross section of the lungs. Brianna was not sure how to deduce the right part with the already existing knowledge. She mistakenly labeled the blue pleural membranes and fluid as diaphragm and left the orange diaphragm without a label.

Brianna: Is this bit the diaphragm or the blue bit?

Charlotte: Oh, that's/

Brianna: The blue bit.

Charlotte: No, that's not the blue bit.

Brianna: Not the blue bit?

Interviewer: Is the blue bit the diaphragm? You decide.

$===$ INSERT Figure 5 Brianna's Annotations HERE===

This seemingly harmless mistake could imply some aspects of her understanding. She simply did not know the concept of the pleural membranes and fluid. As Mr. Duncan usually focused on explaining a big picture of biology concepts, he did not mention the pleural membranes and fluid in class. The textbook had the detailed diagram (Figure 2), but did not elaborate on the function of the pleura either. The pleura are one of the negative analogies of the bell-jar model. If students' understanding of the breathing mechanism was not sophisticated enough to notice the subtle differences between the model and the anatomical diagram, it would be extremely difficult for them to automatically recognize the function of the pleura without additional explanation. As researchers have found, simplistic models could initially help students understand some features of the science concept, but they have a lasting effect and often prevent students from using a 
refined model to develop more sophisticated science concepts (Coll \& Lajium, 2011; Gilbert \& Osborne, 1980; Harrison \& Treagust, 2006). Brianna relied on the model as the primary representation to interpret the anatomical diagram, and consequently, she did not recognize the pleura as relevant or important when studying the topic. If she had been able to compare those different representations critically, she might have been able to build deeper understanding of the concept (not adopting the evaluation strategy). This scenario was backed up by her response for the diagnostic test Item \#9. Although she knew the air-flow was caused by the volume and pressure difference, she chose the statement of active lung expansion rather than one with the thoracic cavity, the pleura, and surface tension. Some new words, such as pleura and surface tension, might have distracted Brianna's thinking from choosing the right statement for the breathing mechanism.

If she had utilized more of her understanding on the diagrammatic conventions for muscle contraction and relaxation, would she have been able to avoid the mistake? Usually, the muscle contraction and relaxation is represented with the change in the thickness and length of the muscle. If muscles contract, they look shorter and thicker. When muscles relax, they look longer and thinner. The thickness of the blue bit (pleural membranes) was the same in the diagram for both inhalation and exhalation, but different for the orange bit (diaphragm). If she considered the thickness change only, she might have been able to point out the diaphragm correctly in the anatomical diagram. However, Brianna might have been aware that the diaphragm was a sheet of skeletal muscle, spanning from one end of the rib cage to the other, like the rubber sheath in the bell jar model. The orange colored bit in the anatomical diagram looked like two separate things rather than one long muscle, while the blue bit looked like a skeletal muscle wrapping around the lungs. Because she was applying her understanding of a simple analogical model to annotate a 
more complex representation, she was not able to decide which diagrammatic conventions to rely upon in order to make correct translation of representations. Naturally, her reliance on the model limited her interpretation of the diagram, and prevented her from critically reexamining her understanding of the model and extending her understanding of the concept to a more scientific one.

\section{Carly's Pursuit of One-to-One Correspondence between Representations}

Similar to Brianna, Carly adopted the application strategy to interpret the anatomical diagram, but unlike Brianna, her integration of representations was done based on her incomplete understanding of the bell jar model and she sought direct one-to-one correspondence between representations. Despite Mr. Duncan's explicit warning of the limitation of the model, Carly did not consider the limitations of the model or the differences between the two representations. She simply sought one-to-one correspondence between those representations when she was trying to integrate them. Consequently, she had difficulty interpreting the anatomical diagram and made several mistakes in explaining the concept in the interview.

Carly was a hard-working student who often sought help from Mr. Duncan, asking questions before and after class. She struggled more than other students at the beginning of the year, but "her grade got better and better" as the school year went on. In this episode, it was obvious that she was trying hard to make sense of the given information. When asked about breathing, Carly and her partner supplied their answers, her partner about inspiration and Carly about expiration.

Cecil: Breathing in is inspiration, and that's where the diaphragm moves down and air comes into the lungs and into the alveoli where it then is diffused into the blood for oxygen and then carbon dioxide diffuses back into the alveoli and 
then...

Carly: Breathing out is expiration which is when the diaphragm contracts more and the air is taken back out of the lungs and the carbon dioxide is taken out through the lungs and came in through the alveoli and out into the air.

Carly was following the structure of her partner's explanation in the interview, but modifying the content - from inspiration to expiration; from air comes in to air taken back out; and from oxygen diffused into the blood to carbon dioxide taken out. Looking at Carly's account closely, however, we can see something is amiss. Carly notes the diaphragm contracts rather than relaxes for expiration. The interviewer asked her to explain the breathing process on the diagrams, and her reasoning became clearer when we look at what she wrote on the diagram (see Figure 6).

\section{$===$ INSERT Figure 6 Carly's Annotations HERE===}

From the annotation on the model diagram, Carly seemed to have grasped the main purpose of the bell-jar model - help understanding the relationship among the movement of the rubber sheet, the difference in air pressure, and the air movement. With a line pointing at the balloons, she wrote, "lungs filling as air pressure becomes lower" for inspiration, and "air is breathed out as pressure inside is higher than the outside" for expiration.

Different from Adele and Brianna, Carly seemed to be making a direct, one-to-one translation from the bell jar model to the human anatomy without carefully considering how the model translates into the target concept. For the rubber sheet movement, she wrote, 'diaphra[g]m moves down' for inspiration and 'diaphra[g]m contracts' for expiration. This explanation corresponds to the earlier remark on the breathing process. If we replace the word "diaphra[g]m" with "rubber sheet," however, the explanation makes sense. "The rubber sheet moves down (or is stretched down)" for the model on the left side, and "the rubber sheet contracts (or moves back 
up to the original position)" for the right. She knew that the pulled-down rubber sheet has a longer length than the one in the normal position. A muscle contraction means a shorter length and relaxation means a longer length. When she combined those two facts, she figured that the pulled-down rubber sheet represents muscle relaxation and the normal position rubber sheet muscle contraction.

When we refer to an analogical model, we try to figure out the analogy and replace each analogous part into what it represents in the scientific target concept. That is exactly what Carly did, but on a misplaced analogy. If she had focused on the increased tension or energy to pull down the rubber sheet instead of the increased length, she might have seen a different correspondence between the bell-jar model and the human breathing mechanism, and given a different explanation. Yet, she focused on the misplaced analogy, and her attempt to translate her interpretation of the model to explain the target concept was not technically correct.

Carly's confusion was evident when she attempted to apply what she understood from the bell-jar model directly to explain the anatomical diagram (the application strategy integrating multiple representations). When we looked at her anatomical diagram closely, we could see that she drew lines pointing only at the diaphragm and the lungs and focused on those two areas. She neglected to label any other body parts, such as the intercostal muscles, ribs, and chest cavity. She did not provide any explanation incorporating other body parts. Mr. Duncan cautioned in his lesson that there were other muscles involved in human breathing and that this particular model was inadequate to represent the whole breathing mechanism. Yet, the model was the principal representation used by Carly to learn about the concept and rely on it. Carly saw breathing mechanism in terms of the lungs and the diaphragm: or more precisely, the balloons and the rubber sheet. 
She initially wrote down the correct explanation for the diaphragm movement during inspiration and expiration on the anatomical diagram. This interpretation could have been an intuitive one because people can easily feel that our muscles are tensing when we take a deep breath, and our bodies become relaxed when we are breathing out. However, Carly realized that what she wrote on the anatomical diagram did not correspond to the bell-jar model explanation she had previously written. She knew that she needed to provide a coherent explanation and align her explanation for the anatomical diagram with the one for the bell-jar model. She crossed out a couple of written words and changed her diagram annotations to correspond to her initial written explanation for the model. For inspiration, "diaphragm contracts moving down" was changed into "diaphragm relaxes moving down." For expiration, "diaphragm relaxes" was changed into "diaphragm contracts." Carly's interpretation of the diagram of the lungs was strongly interfered by her (mis)understanding of the bell-jar model. Like Brianna, she did not carefully examine the diagrammatic conventions to notice the thickening and thinning of the diaphragm.

Yet, she was not fully satisfied with the logic here somehow, and added a contradicting statement for expiration: "[The] lungs to relax expelling air and $\mathrm{CO}_{2}$ out" while "[the] diaphragm contracts." It was interesting to notice that while pursuing the one-to-one correspondence between the target concept, the model and the diagram, Carly had written this contradicting statement with the lungs and the diaphragm. When the interviewer asked Carly to elaborate on her diagram annotations, she basically reiterated what she had written on the diagram, without referring to the relaxing of the lungs.

Carly: um, so the diaphragm does relax [during inhalation], and then it causes the, um, lungs to expand and the air from outside you breathe in comes in and then it diffuses into the al-vi, like, oxygen diffuses into the blood and then 
carbon dioxide diffuses back into the alveoli, and then when you breathe out, your diaphragm contracts and the blood, the carbon dioxide, and excess oxygen is breathed out again.

Carly's misplaced reliance on the model limited her understanding of the other representation. Her incomplete understanding of the concept was shown in the diagnostic test as well. For Item \#6, she thought that the breathing mechanism was caused solely by the diaphragm movement_- “[the lungs'] volume changes because the diaphragm pushes and pulls on them"without the involvement of intercostal muscles. While Carly explained, in the interview, that the volume and pressure change of the lungs due to the diaphragm movement was the direct cause of inspiration and expiration, she selected a statement of the reverse effect for the diagnostic test Item \# 9. Her chosen answer reads, "Air moving into the lungs forces them to expand to let the air in and as the air moves out the lungs decrease in volume because there is less air to fill them." This contradicting explanation of the cause and effect of breathing implies that her interpretation of the bell jar model and of the written text was not coherent, just like her annotations of the anatomical diagram (for the diaphragm contraction and the lung relaxation). Although she was mechanically pursuing one-to-one correspondence between the analogical model and the target concept in the interview, she did not display coherent understanding in her diagnostic test.

Carly was not the only student struggling with using the model to construct a scientific understanding of the target concept. The difficulty seems to be partly due to the limitation of the bell-jar model itself with its inherent negative analogies (Eilam, 2013; Yip, 1998), but partly to students' limited understanding in how they could utilize different representations to develop and explain their understanding of a science concept. Because Carly did not fully develop the representational fluency to understand the nature of analogical models, she was not able to use 
the application strategy successfully and examine the correspondence of the model to the target concept critically, preventing her from utilizing the particular model to more deeply develop her understanding.

After analyzing her limited use of strategies with multiple representations and her confusion, we cannot help wondering what would have happened if she had utilized the multiple representations in more than one way. If she had regarded the bell-jar model and the anatomical diagram as complementary, how differently would she have interpreted the anatomical diagram? Would she have provided two different explanations for the breathing mechanism, one for the model and the other for the diagram? What if Carly had been able to extend her initial understanding of the anatomical diagram to reinterpret the bell-jar model, like Adele did, rather than the other way around? Would she have succeeded in integrating her understanding to build a more scientific explanation or would she have given the same explanation? We have no way of answering those what-if questions with confidence, but Carly's way of using multiple representations invokes such questions for science educators.

\section{Analyzing Students' Strategies with Representations through the Framework}

To understand the students' learning with multiple representations, we have analyzed students' explanations for the topic of human breathing mechanism with a bell-jar model and an anatomical diagram. We have identified the perceived functions of the representations and the representation integration strategies that learners had used. Table 1 summarizes how the coding scheme was operationalized in this particular combination of representations for the topic, and Table 2 summarizes each student's strategies with multiple representations and their two-tier test results. In this particular combination of a bell-jar model and an anatomical diagram, the most favored strategy by the students was the 'applying the understanding of one representation to 
interpret the other representation' strategy. All students used this strategy, but their primary representation to interpret the other was different and so was their explanation of the concept. $===$ INSERT Table 2 Analysis of Students' Strategies and Test Results HERE=== The majority of participating students used their understanding of the more familiar representation, the bell-jar model which the teacher presented in class, to interpret the more complex representation, the anatomical diagram from the textbook. When they attempted to integrate these two representations, they focused on the corresponding body parts and functions between the bell-jar model and the anatomical diagram (such as the diaphragm movement and the change in the volume of the lungs) and did not pay close attention to the different aspects of each representation (for example, intercostal muscles and ribs) or to diagrammatic conventions (muscle thinning or thickening). Because they relied mostly on what they knew about the model to interpret the anatomical diagram, their initial understanding of the bell-jar model and the level of correspondence they were seeking played a significant role in constructing their understanding of the breathing mechanism concept. Brianna and Carly, for example, adopted the application strategy with the bell-jar model as the primary representation. Brianna (and Brooke) had a reasonably good understanding of the bell-jar model itself, and she was able to integrate those two representations to explain the human breathing mechanism better than Carly (and Cecil, Cathy, and Charlotte), who sought direct one-to-one correspondence between representations as noted above.

Abby and Adele, on the other hand, adopted this application strategy in reverse. They chose the anatomical diagram (more complex representation) as the primary representation to explain the bell-jar model (simpler representation). Instead of finding direct one-to-one correspondence between representations, these two students attended to the different aspects of 
each representation carefully. They critically evaluated the representations and recognized the main goals and limitations of each representation (evaluation strategy). Based on the critical evaluation, they effectively selected different features of each representation and utilized these features when explaining the science concept (complementary strategy). Because they figured out what the representations illustrated in relation to each other, they were neither hampered by the negative analogs of the bell-jar model nor did they seek a direct one-to-one correspondence between representations. Their understanding of the concept and of the nature of representations was comprehensive enough to allow them to flexibly reinterpret the bell-jar model based on their understanding of the anatomical diagram. In this sense, their application strategy was significantly different from the other students' application strategy.

Learning with multiple representations always entails processing and applying different sets of information which inevitably involves strategic decisions and a certain degree of risk, especially when it involves an analogical model. As Gericke, Hagberg, and Jorde (2013) found, students often have difficulty not only in discerning the differences in various models and the conceptual variations, but also in applying their general knowledge about models into content specific models. Yet, the limitations of the bell-jar model amplified the risks for students in using the application strategy with the model as the primary representation. Due to the limitations of the analogical model, the students' decision to adopt the evaluation strategy and recognize the purpose and limitations of each representation played a significant role in whether or not they were able to construct a coherent and scientific understanding of the breathing mechanism concept.

Overall, being able to adopt multiple strategies for relating different representations has played a crucial role for those students who were able to offer a coherent, effective explanation 
of the concept. Brianna and Carly adopted the application strategy without trying out other strategies. They stuck with their initial strategy, even when they found something was not quite right. On the other hand, Adele tried out all three strategies to establish the relationship between the model and the diagram and to communicate her understanding better. After exhausting all three strategies of integration, she critically examined her understanding of the representations and settled on her explanation on the science concept. We recognize that it may not be necessary for students to apply all three strategies to integrate different representations for every combination of representations in order to construct a deeper understanding for a science topic. Nevertheless, this analysis shows that those students who adopted extra strategies were able to reexamine their understandings and communicate them effectively and develop a coherent understanding of the concept.

In the analysis, we saw some variations in the students' integration strategies as we described above, but some subcategory strategies were not observed. For example, Ainsworth (2008) listed two subcategories for the complementary strategy: different information and different process. We saw Adele and Abby using the complementary strategy for explaining different aspects of the science concept (subcategory of accessing different content), but not using them for different processes. The same point applies for the evaluation strategy. We did not observe any students using the representations to 'draw the underlying concept from multiple data' or 'extend the understanding of one representation to create another representation' because the given combination of multiple representations did not involve multiple data or situations and we did not ask students to create a new representation in the interview. Even though the students' approaches to integrating representations were diverse, this particular combination of representations in this setup led students to adopt a certain set of strategies, but not all strategies 
to the subcategory level. Future studies may need to involve different sets of representations to see how students utilize various strategies and decide how students' actual strategies interact with the anticipated functions of multiple representations.

\section{CONCLUSIONS}

Understanding and communicating science through multiple representations is an essential aspect of science education, and many educational researchers have identified the need to recognize the varying paths of students' learning with multiple representations and to encourage constructive science learning experiences (Ainsworth et al., 2011; Gilbert, 2005; National Research Council, 2009). In this study, we modified Ainsworth's (2006, 2008) taxonomy of functions of multiple representations and used it as the analytical framework. By adapting Ainsworth's framework for this study, we were able to identify the students' learning strategies with multiple representations when explaining a science topic they have studied and why they were more or less successful in offering a coherent explanation on the human breathing mechanism. In this paper, we gave a detailed view on students' different strategies of utilizing multiple representations with three focus students. Adele, the most confident among the focus students, was able to freely adopt the three strategies of utilizing multiple representationscomplementary, application, and evaluation strategies. She already had a good understanding of the concept and of the nature of multiple representations. She recognized the different purpose of each representation, critically examined the limitations, and creatively related different representations in order to effectively communicate her conceptual understanding. Brianna, the uncertain one, had a relatively good understanding on the main features of the model. Yet, her understanding of the concept and of the nature of representations was not comprehensive enough 
to adopt all three strategies of multiple representations. She mainly relied on the application strategy and did not progress into developing more comprehensive understanding of the concept by deciphering subtle clues or critically evaluating representations. Carly, the seeker of mechanical one-to-one correspondence across different representations, became confused with the analogies of the model and applied her misunderstanding to interpret the other representation. Carly's adoption of the single strategy of application was similar to Brianna, but different from her, Carly's understanding of the primary representation, the model, was inconsistent with the scientific interpretation, and the insistence on direct one-to-one correspondence resulted in Carly's mixed-up understanding of the target science concept.

Initially, the researchers realized some difficulty in pinpointing the students' learning strategies with representations because the manner in which students used the multiple representations was not static but was continuously changing during the interview. However, once we finalized the coding scheme and conducted the micro-analysis of students' interviews in relation to their annotations of diagrams and diagnostic test results, the adapted framework from Ainsworth proved to be instrumental in analyzing how students are making sense of multiple representations to understand and explain the concept. By extensively referring to the analytical framework developed in this paper, we have illustrated how teachers and educational researchers can adopt Ainsworth's framework to analyze students' explanations when learning from multiple representations. We encourage science educators to adopt this analytical framework to evaluate how teachers could enhance students' strategies to integrate multiple representations for better conceptual understanding and improved communication.

As noted in the introduction, there has been much interest in students' explanations of scientific phenomena when they are presented with multiple representations such as analogies, 
models or simulations. The findings of these studies generally have shown that the learning outcomes are enhanced with multiple representations (Chittleborough et al., 2005; Eilam \& Poyas, 2010; Harrison \& Treagust, 2006). However, none of these studies have provided any details of the strategies that students use to bring about these enhanced understandings. The study reported in this article makes an important and, we believe, unique contribution in this regard by describing, with an analytical framework adapted from Ainsworth, the learning strategies that students use when presented with more than one representation of a scientific phenomenon. In terms of research into learning, the article has shown that a deeper analysis of students' learning strategies with multiple representations is a complex process that gives rise to different kinds of learning outcomes. From a practical point of view for the classroom teacher, we were encouraged by the responses of Mr. Duncan to the data we showed him - these different analyses of student learning strategies and learning outcomes from his teaching provided him with valuable insights into his own teaching. 


\section{REFERENCES}

Adadan, E., Irving, K. E., \& Trundle, K. C. (2009). Impacts of multi-representational instruction on high school students' conceptual understandings of the particulate nature of matter. International Journal of Science Education, 31(13), 1743-1775.

Adams, W. K., \& Wieman, C. E. (2011). Development and validation of instruments to measure learning of expert-like thinking. International Journal of Science Education, 33(9), 12891312.

Ainsworth, S. (1999). The functions of multiple representations. Computers \& Education, 32(23), 131-152.

Ainsworth, S. (2006). DeFT: A conceptual framework for learning with multiple representations. Learning and Instruction, 16(3), 183-198.

Ainsworth, S. (2008). The educational value of multiple-representations when learning complex scientific concepts. In J. K. Gilbert \& M. Reiner \& M. Nakhleh (Eds.), Visualization: Theory and practice in science education (pp. 191-208). Dordrecht, Netherlands: Springer.

Ainsworth, S., Bibby, P. A., \& Wood, D. J. (1998). Analysing the costs and benefits of multirepresentational learning environments. In M. W. van Someren \& P. Reimann \& H. P. A. Boshuizen \& T. de Jong (Eds.), Learning with multiple representations (pp. 120-134). Oxford, UK: Pergamon.

Ainsworth, S., Prain, V., \& Tytler, R. (2011). Drawing to learn in science. Science, 333(6046), 1096-1097.

Anderson, C. W., Sheldon, T. H., \& Dubay, J. (1990). The effects of instruction on college nonmajors conceptions of respiration and photosynthesis. Journal of Research in Science 
Teaching, 27(8), 761-776.

Aubusson, P. J., Harrison, A. G., \& Ritchie, S. M. (Eds.). (2006). Metaphor and analogy in science education. Dordrecht, Netherlands: Springer.

Chittleborough, G., Treagust, D. F., Mamiala, T. L., \& Mocerino, M. (2005). Students' perceptions of the role of models in the process of science and in the process of learning. Research in Science \& Technological Education, 23(2), 195-212.

Cohen, L., Manion, L., \& Morrison, K. (2011). Research methods in education (7th ed.). London: Routledge.

Coll, R. K., \& Lajium, D. (2011). Modeling and the future of science learning. In M. S. Khine \& I. M. Saleh (Eds.), Models and modeling: Cognitive tools for scientific enquiry (pp. 321). Dordrecht, Netherlands: Springer.

Cook, M., Carter, G., \& Wiebe, E. N. (2008). The interpretation of cellular transport graphics by students with low and high prior knowledge. International Journal of Science Education, 30(2), 239-261.

Dagher, Z. R. (1995). Review of studies on the effectiveness of instructional analogies in science education. Science Education, 79(3), 295-312.

de Jong, T., Ainsworth, S., Dobson, M., van der Hulst, A., Levonen, J., Reimann, P., Sime, J.-A., van Someren, M. W., Spada, H., \& Swaak, J. (1998). Acquiring knowlege in science and mathematics: The use of multiple representations in technology-based learning environments. In M. W. van Someren \& P. Reimann \& H. P. A. Boshuizen \& T. de Jong (Eds.), Learning with multiple representations (pp. 9-40). Oxford, UK: Pergamon. diSessa, A. A., \& Sherin, B. L. (2000). Meta-representation: an introduction. The Journal of Mathematical Behavior, 19(4), 385-398. 
Dori, Y. J., \& Belcher, J. (2005). Learning elecgtromagnetism with visualizations and active learning. In J. K. Gilbert (Ed.), Visualization in science education (pp. 198-216). Dordrecht, Netherlands: Springer.

Eilam, B. (2013). Possible constraints of visualization in biology: Challenges in learning with multiple representations. In D. F. Treagust \& C.-Y. Tsui (Eds.), Multiple representations in biological education (pp. 55-73). Dordrecht, Netherlands: Springer.

Eilam, B., \& Poyas, Y. (2010). External visual representations in science learning: The case of relations among system components. International Journal of Science Education, 32(17), $2335-2366$.

Erickson, F. (2012). Qualitative research methods for science education. In B. J. Fraser \& K. G. Tobin \& C. J. McRobbie (Eds.), Second international handbook of science education (Vol. 2, pp. 1451-1469). Dordrecht, Netherlands: Springer.

Gericke, N., Hagberg, M., \& Jorde, D. (2013). Upper secondary students' understanding of the use of multiple models in biology textbooks-The importance of conceptual variation and incommensurability. Research in Science Education, 43(2), 755-780.

Gilbert, J. K. (2004). Models and modeling: Routes to more authentic science education. International Journal of Science and Mathematics Education, 2(2), 115-130.

Gilbert, J. K. (2005). Visualization: A metacognitive skill in science and science education. In J. Gilbert (Ed.), Visualization in Science Education (pp. 9-27). Dordrecht, Netherlands: Springer

Gilbert, J. K., \& Osborne, R. J. (1980). The use of models in science and science teaching. European Journal of Science Education, 2(1), 3-13.

Gilbert, J. K., \& Treagust, D. F. (Eds.). (2009). Multiple representations in chemical education. 
Dordrecht, Netherlands: Springer.

Glynn, S. M. (2008). Making science concepts meaningful to students: Teaching with analogies. In S. Mikelskis-Seifert \& U. Ringelband \& M. Brückmann (Eds.), Four decades of research in science education: From curriculum development to quality improvement (pp. 113-125). Münster, Germany: Waxmann.

Gobert, J. D., O’Dwyer, L., Horwitz, P., Buckley, B. C., Levy, S. T., \& Wilensky, U. (2011). Examining the relationship between students' understanding of the nature of models and conceptual learning in biology, physics, and chemistry. International Journal of Science Education, 33(5), 653-684.

Goldman, S. R. (2003). Learning in complex domains: when and why do multiple representations help? Learning and Instruction, 13, 239-244.

Grosslight, L., Unger, C., Jay, E., \& Smith, C. L. (1991). Understanding models and their use in science: Conceptions of middle and high school students and experts. Journal of Research in Science Teaching, 28(9), 799-822.

Harrison, A. G., \& Treagust, D. F. (1998). Modelling in science lessons: Are there better ways to learn with models? School Science and Mathematics, 98(8), 420-429.

Harrison, A. G., \& Treagust, D. F. (2000a). Learning about atoms, molecules and chemical bonds: A case-study of multiple model use in grade 11 chemistry. Science Education, $84(352-381)$.

Harrison, A. G., \& Treagust, D. F. (2000b). A typology of school science models. International Journal of Science Education, 22(9), 1011-1026.

Harrison, A. G., \& Treagust, D. F. (2006). Teaching and learning with analogies : Friend or foe. In P. J. Aubusson \& A. G. Harrison \& S. M. Ritchie (Eds.), Metaphor and analogy in 
science education (pp. 11-24). Dordrecht, Netherlands: Springer.

Hesse, M. B. (1966). Models and analogies in science. Notre Dame, Indiana: Notre Dame University Press.

Kozma, R. (2003). The material features of multiple representations and their cognitive and social affordances for science understanding. Learning and Instruction, 13, 205-226.

Latour, B. (1986). Visualisation and cognition: Drawing things together. In H. Kuklick \& E. Long (Eds.), Knowledge and society studies in the sociology of culture past and present (Vol. 6, pp. 1-40). Greenwich, CT: JAI Press.

Lowe, R. K. (2003). Animation and learning: selective processing of information in dynamic graphics. Learning and Instruction, 13, 157-176.

Mann, M., \& Treagust, D. F. (1998). A pencil and paper instrument to diagnose students' conceptions of breathing, gas exchange and respiration. Australian Science Teachers' Journal, 44(2), 55-59.

Merriam, S. B. (2009). Qualitative research: A guide to design and implementation. San Francisco: Jossey-Bass.

National Research Council. (2009). A new biology for the 21st century. Washington, D.C.: National Academic Press.

Pozzer, L. L., \& Roth, W.-M. (2003). Prevalence, function, and structure of photographs in high school biology textbooks. Journal of Research in Science Teaching, 40(10), 1089-1114.

Prain, V., Tytler, R., \& Peterson, S. (2009). Multiple Representation in Learning About Evaporation. International Journal of Science Education, 31(6), 787-808.

Savelsberg, E. R., de Jong, T., \& Ferguson-Hessler, M. G. M. (1998). Competence-related differences in problem representations: A study in physics problem solving. In M. W. van 
Someren \& P. Reimann \& H. P. A. Boshuizen \& T. de Jong (Eds.), Learning with multiple representations (pp. 263-282). Oxford, UK: Pergamon.

Scanlon, E. (1998). How beginning students use graphs of motion. In M. W. van Someren \& P. Reimann \& H. P. A. Boshuizen \& T. de Jong (Eds.), Learning with multiple representations (pp. 67-86). Oxford, UK: Pergamon.

Schijf, H. J. M., \& Simon, H. A. (1998). One person, multiple representations: An analysis of a simple, realistic multiple representation learning task. In M. W. van Someren \& P. Reimann \& H. P. A. Boshuizen \& T. de Jong (Eds.), Learning with multiple representations (pp. 197-235). Oxford, UK: Pergamon.

Schnotz, W., \& Bannert, M. (2003). Construction and interference in learning from multiple representation. Learning and Instruction, 13, 141-156.

Seufert, T. (2003). Supporting coherence formation in learning from multiple representations. Learning and Instruction, 13, 227-237.

Seymour, J., \& Longden, B. (1991). Respiration--That's breathing isn't it? Journal of Biological Education, 25(3), 177-183.

Tasker, R., \& Dalton, R. (2008). Visualizing the molecular world - Design, evaluation, and use of animations. In J. K. Gilbert \& M. Reiner \& M. Nakhleh (Eds.), Visualization: Theory and practice in science education (pp. 103-131). Dordrecht, Netherlands: Springer.

Treagust, D. F., Chittleborough, G., \& Mamiala, T. (2003). The role of submicroscopic and symbolic representations in chemical explanations. International Journal of Science Education, 25(11), 1353-1368.

Treagust, D. F., Chittleborough, G., \& Mamiala, T. L. (2002). Students' understanding of the role of scientific models in learning science. International Journal of Science Education, 
24(4), 357-368.

Treagust, D. F., Harrison, A. G., \& Venville, G. (1998). Teaching science effectively with analogies: An approach for preservice and inservice teacher education. Journal of Science Teacher Education, 9(2), 85-101.

Treagust, D. F., \& Tsui, C.-Y. (Eds.). (2013). Multiple representations in biological education. Dordrecht, Netherlands: Springer.

Tsui, C.-Y., \& Treagust, D. F. (2003). Genetics reasoning with multiple external representations. Research in Science Education, 33(1), 111-135.

Tytler, R., Prain, V., Hubber, P., \& Waldrip, B. (2013). Constructing representations to learn in science. Rotterdam, Netherlands: Sense.

van Someren, M. W., Boshuizen, H. P. A., de Jong, T., \& Reimann, P. (1998). Introduction. In M. W. van Someren \& P. Reimann \& H. P. A. Boshuizen \& T. de Jong (Eds.), Learning with multiple representations (pp. 1-5). Oxford, UK: Pergamon.

van Someren, M. W., Reimann, P., Boshuizen, H. P. A., \& de Jong, T. (Eds.). (1998). Learning with multiple representations. Oxford, UK: Pergamon.

Waldrip, B., Prain, V., \& Carolan, J. (2010). Using multi-modal representations to improve learning in junior secondary science. Research in Science Education, 40(1), 65-80.

Wartofsky, M. W. (1979). Models: Representation and the scientific understanding. Dordrecht, Holland: D. Reidel Publishing.

White, B. Y., \& Frederiksen, J. R. (1990). Causal model progressions as a foundation for intelligent learning environments. Artificial Intelligence, 42(1), 99-157.

Wilbers, J., \& Duit, R. (2006). Post-festum and heuristic analogies. In P. J. Aubusson \& A. G. Harrison \& S. M. Ritchie (Eds.), Metaphor and analogy in science education (pp. 37-49). 
Dordrecht, Netherlands: Springer.

Wu, H.-K., Lin, Y.-F., \& Hsu, Y.-S. (2012). Effects of representation sequences and spatial ability on students' scientific understandings about the mechanism of breathing. Instructional Science.

Yin, R. K. (2009). Case study research: Design and methods. Thousands Oaks, CA: Sage.

Yip, D.-y. (1998). An improved model for demonstrating the mechanism of breathing. American Biology Teacher, 60(7), 528-530. 


\section{TABLES}

Table 1. Coding Scheme of Learning Strategies with Multiple Representations.

Table 2. Analysis of Students' Strategies with Representations through the Framework and Their Two-Tier Test Results. 


\section{FIGURES}

Figure 1. Strategies of integrating multiple representations for learning (adapted from Ainsworth's (2008) framework).

Figure 2. The breathing mechanism diagram from the Human Biology textbook. From "The sequence of events that occur during (a) inspiration and (b) expiration" by T. J. Newton \& A. P. Joyce (2008). Human Perspectives 2A/2B Book 1. ( $5^{\text {th }}$ ed.) p. 85. C2012 Cengage Learning Australia Pty Limited. Reproduced with the permission of Cengage Learning.

Figure 3. Bell-jar model (a) inspiration and (b) expiration.

Figure 4. Adele's annotations on the diagrams

Figure 5. Brianna's annotations on the diagram

Figure 6. Carly's annotations on the diagram 


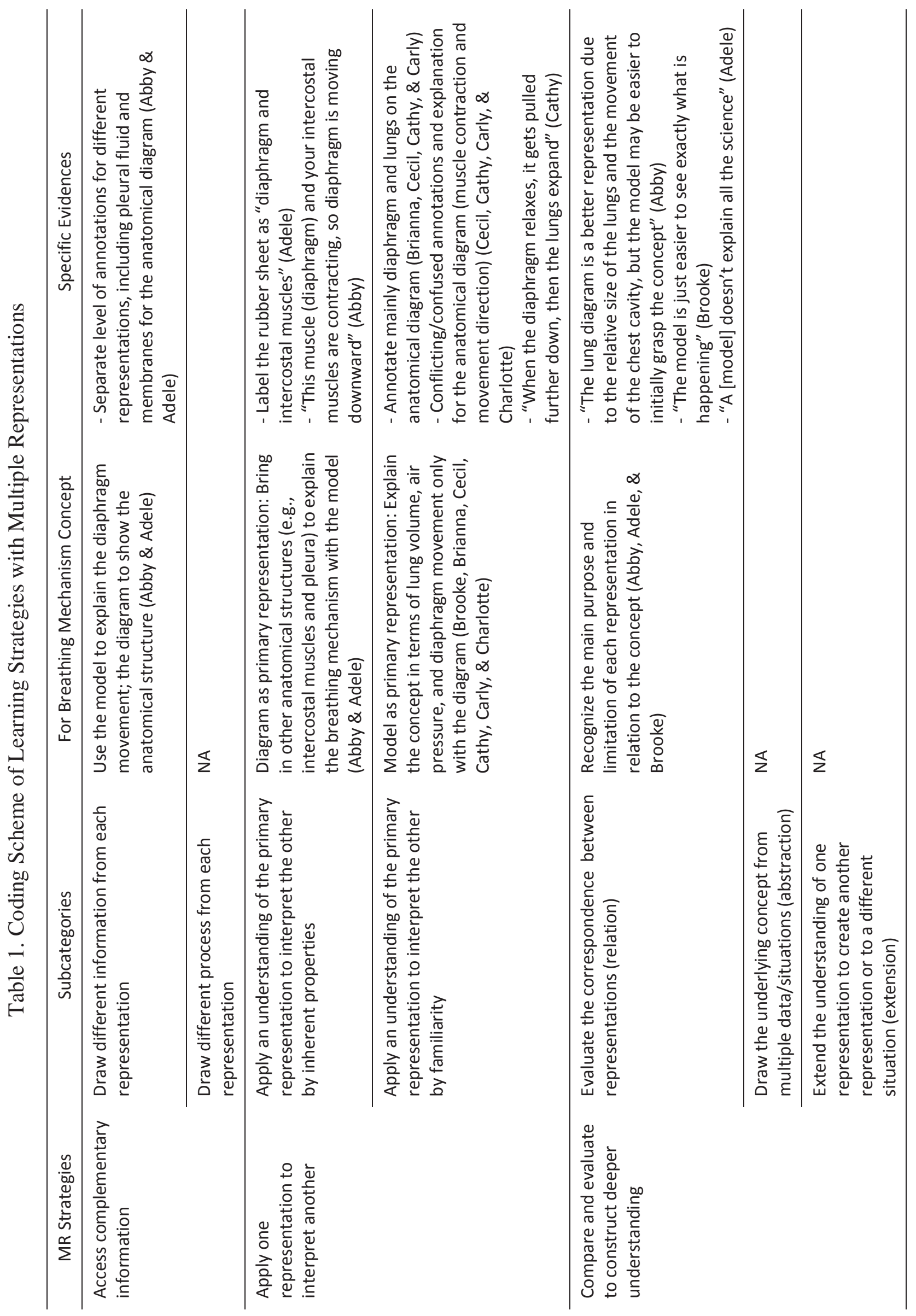




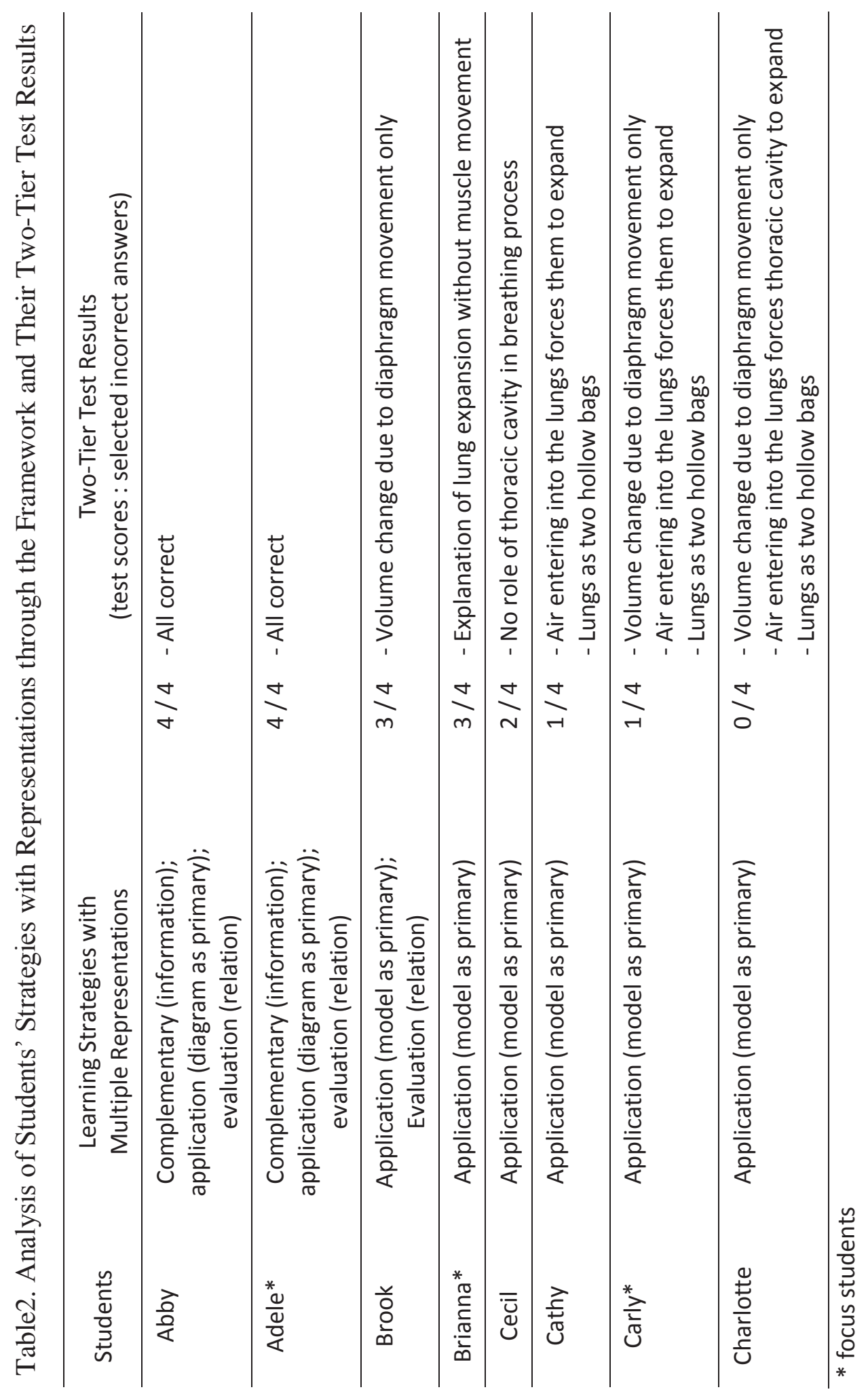


Figure 1. Strategies of integrating multiple representations for learning (adapted from Ainsworth’s (2008) framework)

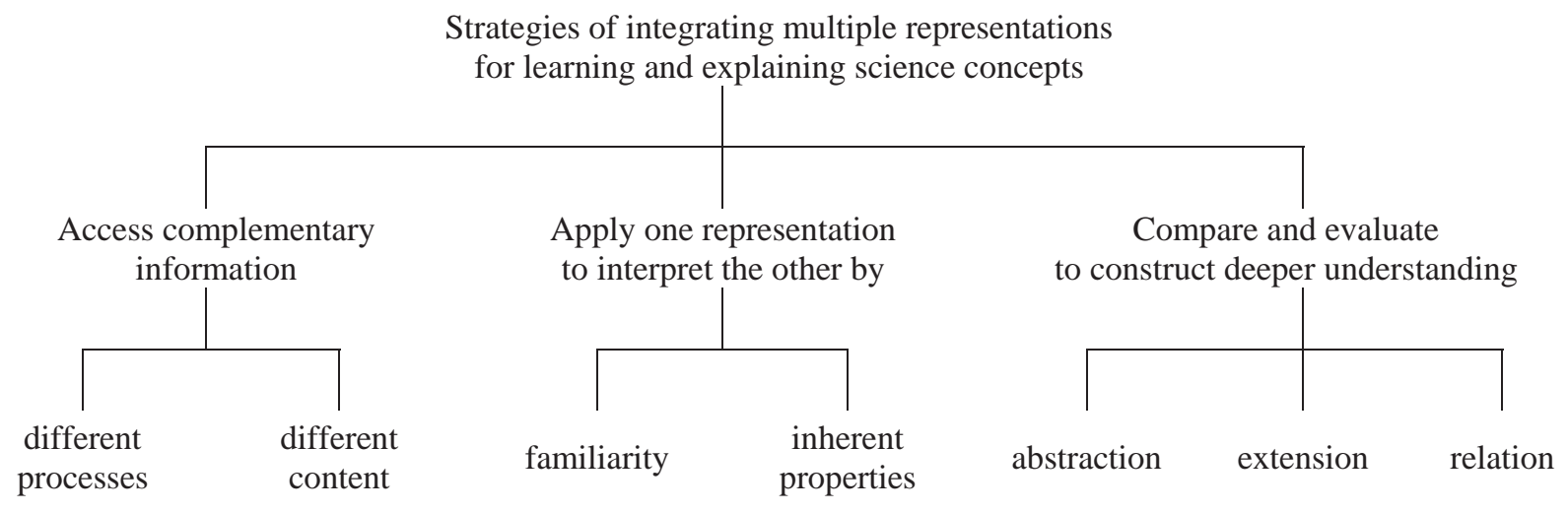




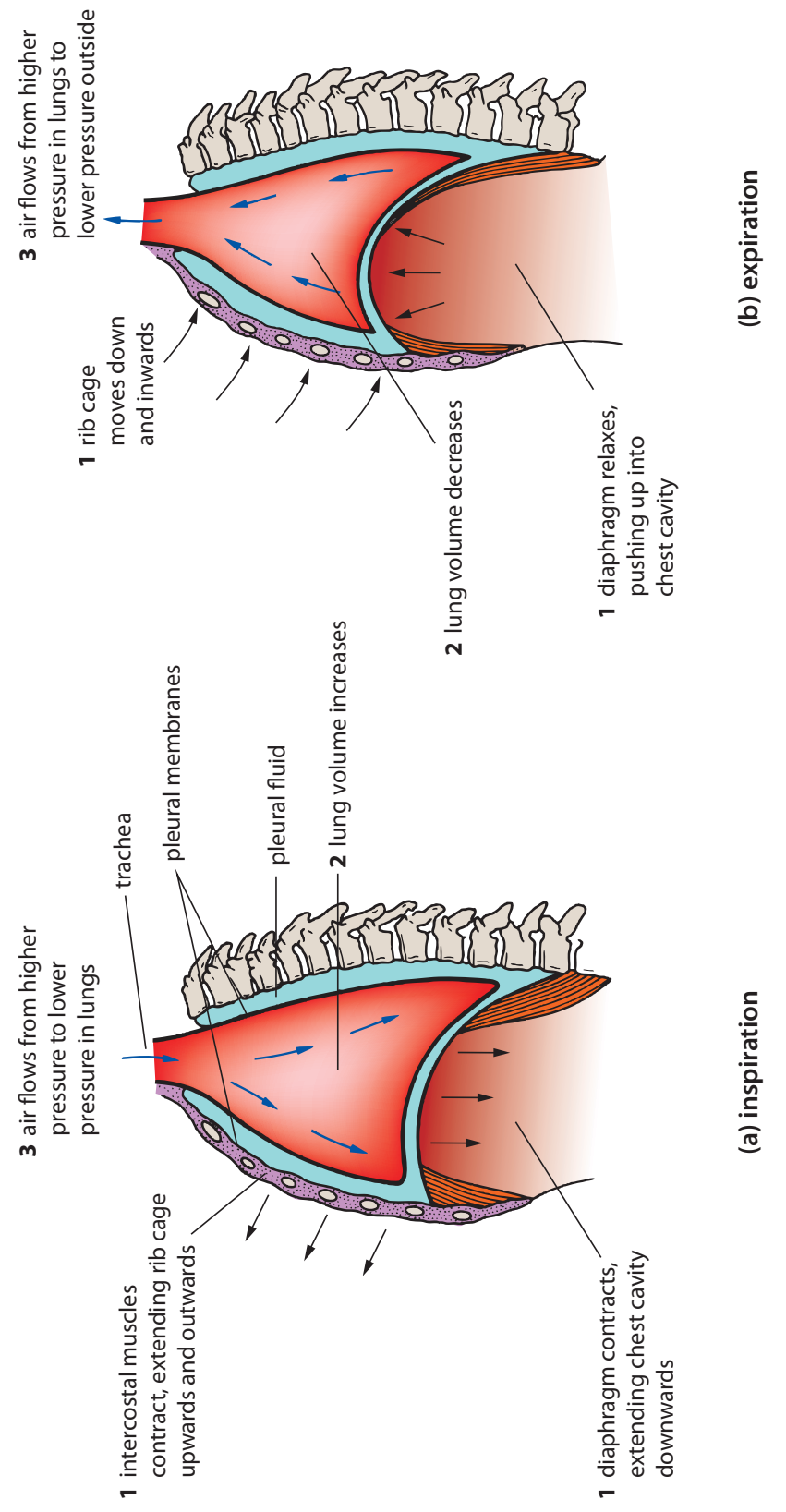




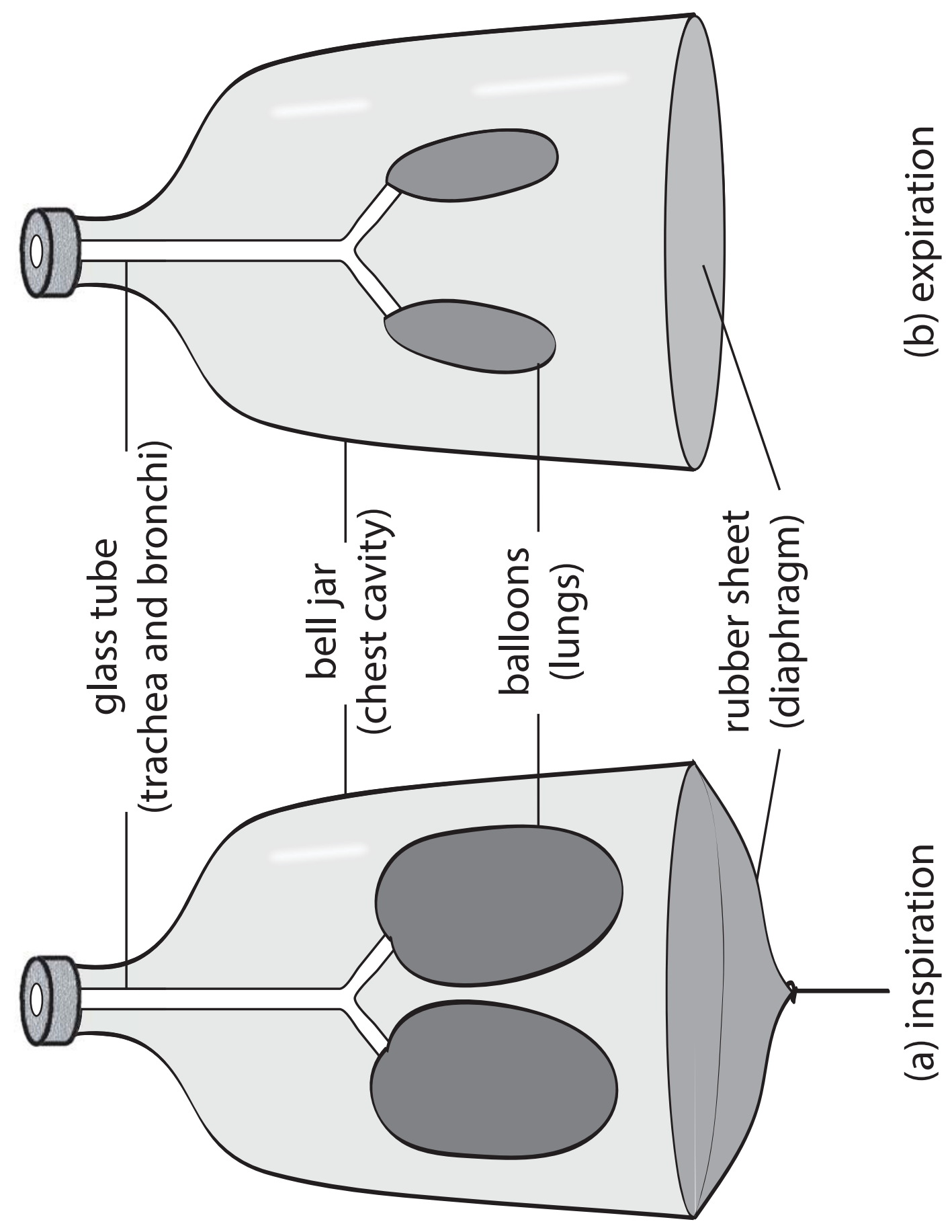



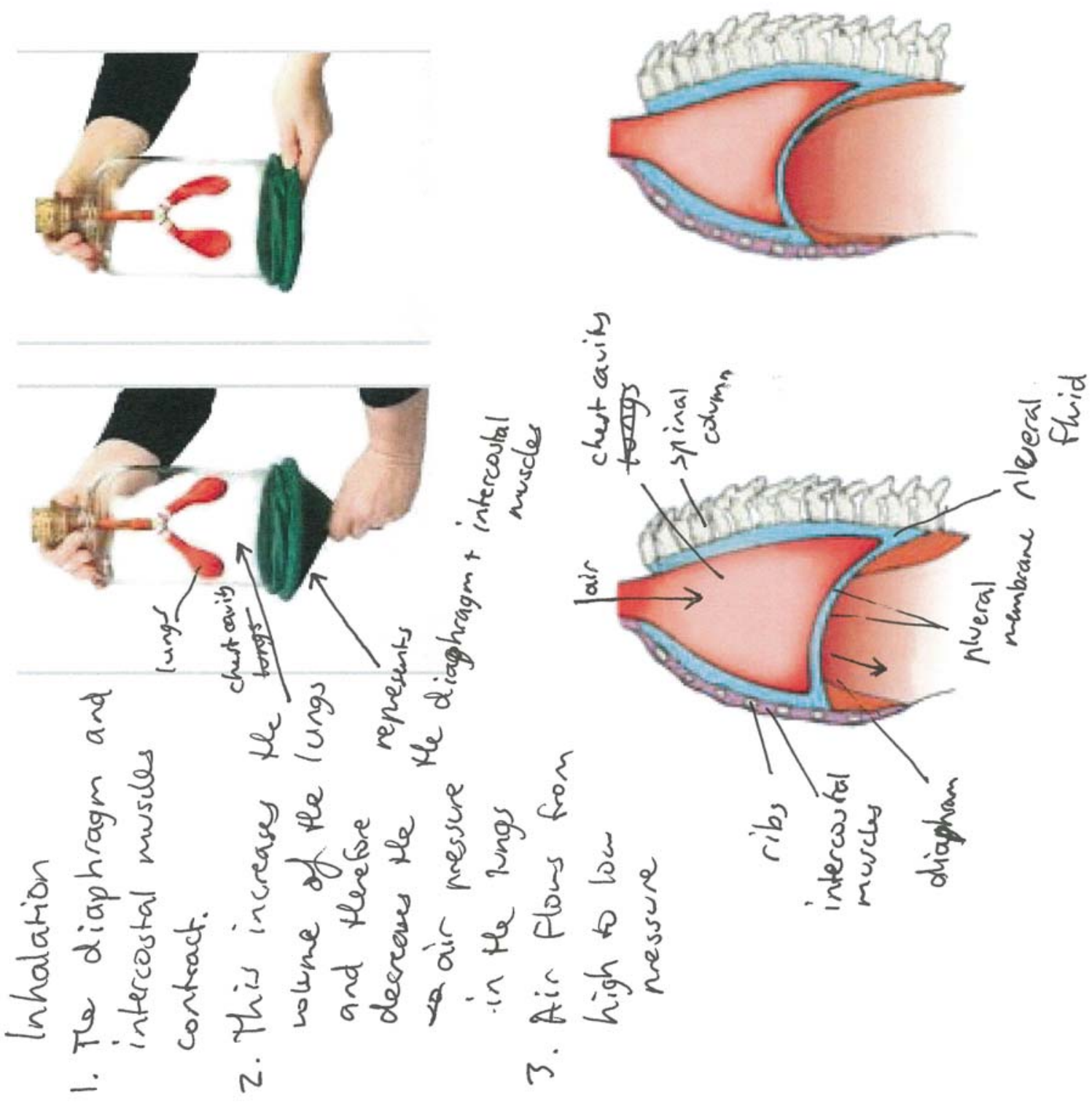

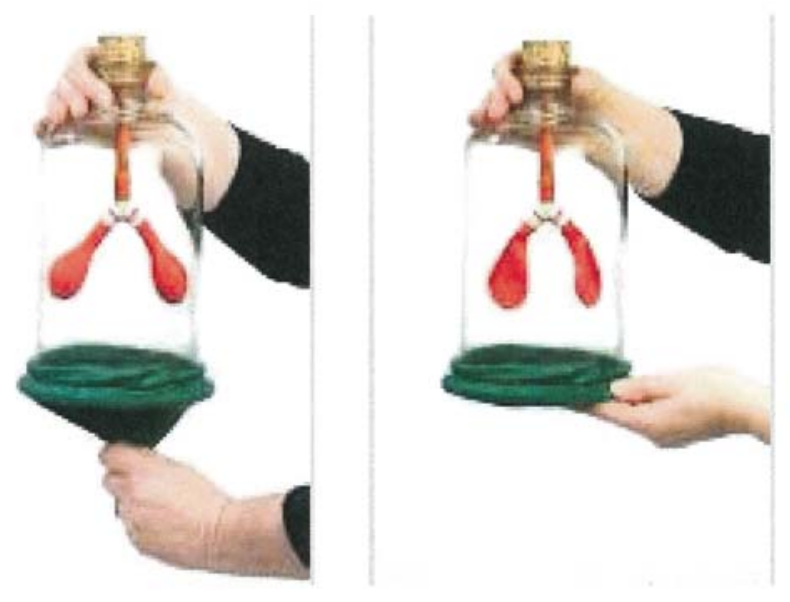

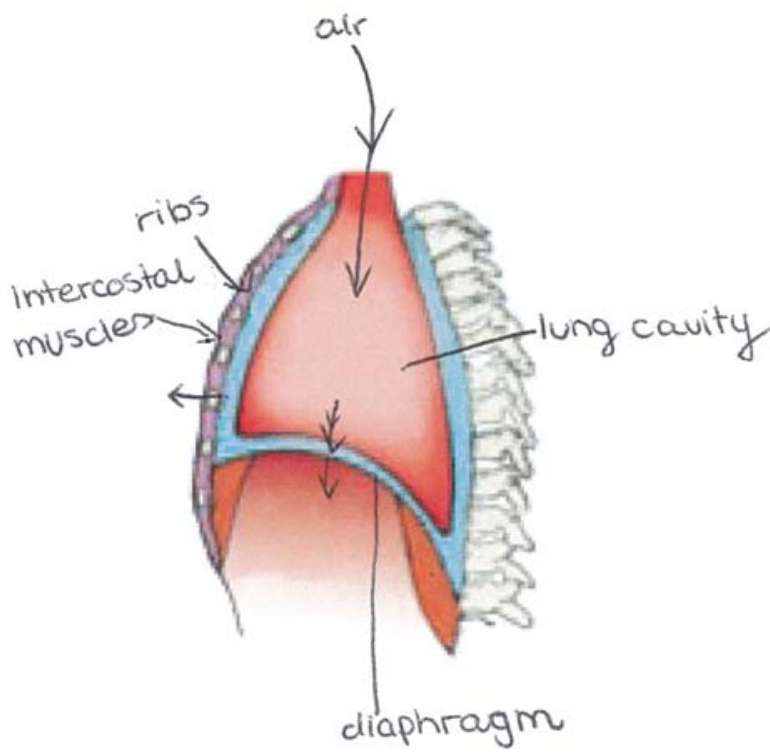

In halation

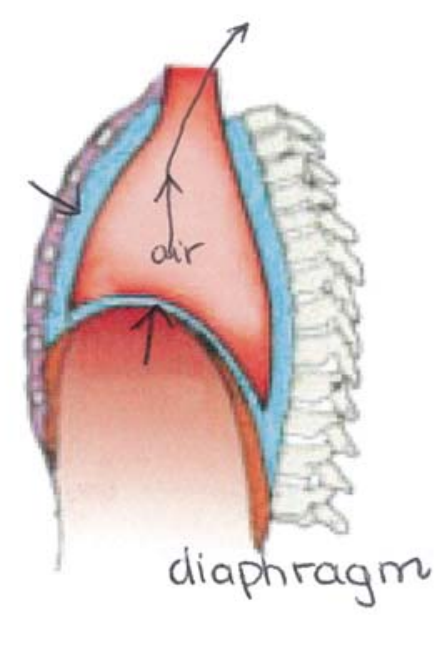

Exhalation 

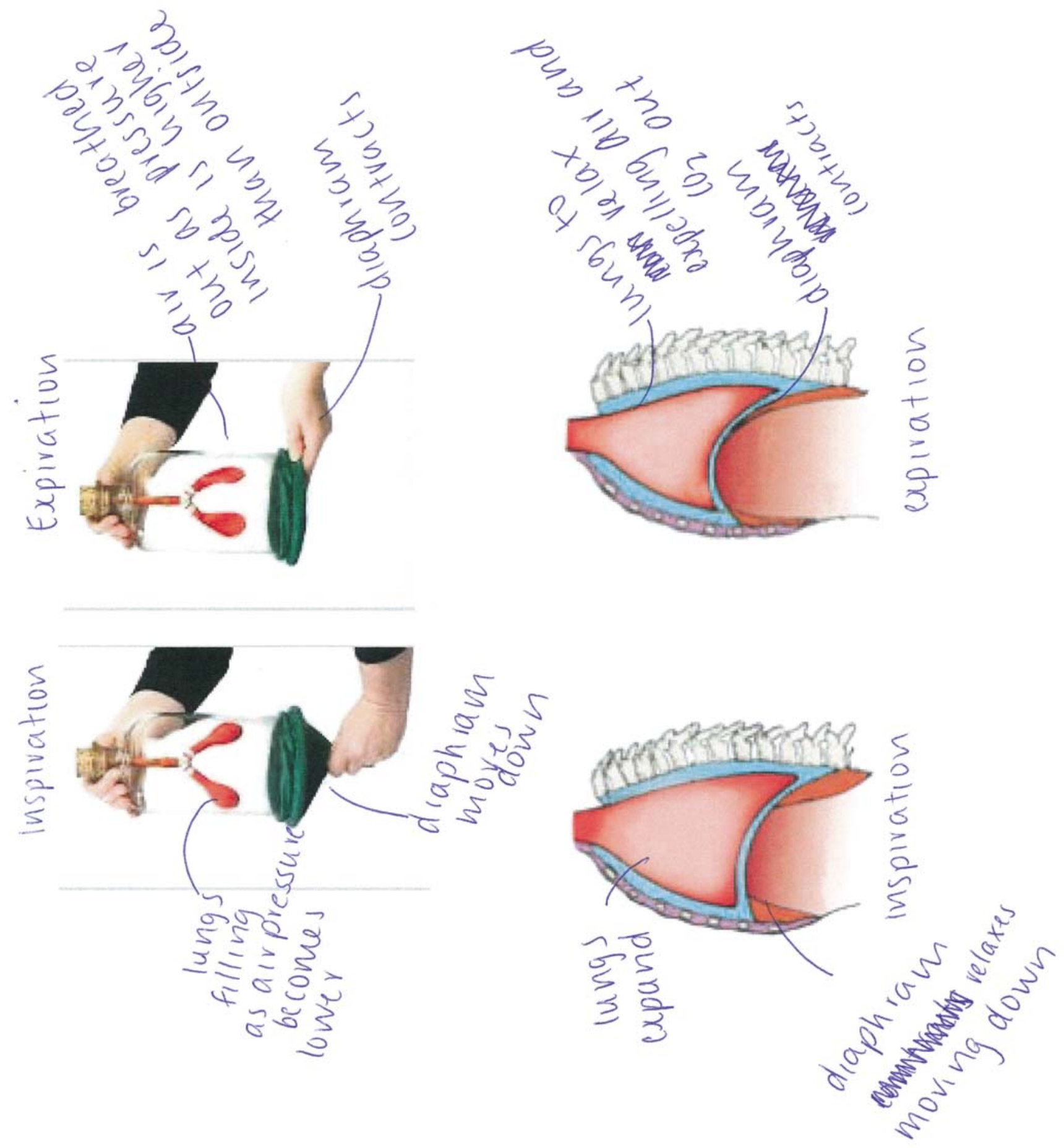